\title{
Role of Catalytic Synthesis on Growth and Distribution of Platinum Nanoparticle on Carbon Nanotube Surface
}

\author{
Rike Yudianti ${ }^{1, *}$, Holia Onggo $^{1}$, Indriyati ${ }^{1}$, Sudirman $^{2}$ \\ ${ }^{1}$ Research Center for Physics, Indonesian Institute of Sciences, Jalan Cisitu no. 21/154D, Bandung, 40135, West Java, Indonesia \\ ${ }^{2}$ Department of Chemistry, University of Indonesian, Kampus Baru UI, Depok, Indonesia
}

\begin{abstract}
Utilization of Pt/CNT nanohybride in development of PEMFC electrocatalyst is being studied extensively. In the current study, CNT-based electrocatalyst synthesis was carried out by chemical reduction using ethylene glycol as reducing agent to evaluate the regulation of the synthesis condition on $\mathrm{Pt}$ size distribution and the electrocatalytic performance. Role of nitrogen purge and ethylene glycol (EG) on the synthesis promotes a fairly good Pt distribution. Existence of water in the synthesis causes rapid growth of Pt nanoparticle forming some flocking particles on the CNT surface. Evaluation of $\mathrm{Pt}$ size distribution on functionalized MWCNT surface was performed by transmission electron microscope (TEM) as appropriate tool for direct visualization. The own-synthesis electrocatalyst using A- $\mathrm{N}_{2}$ synthesis condition exhibits good Pt architecture and electrochemical performance corresponding to eletrocatalytic active surface area (EAS). The whole analysis of electrocatalyst was evaluated in this paper.
\end{abstract}

Keywords Electrocatalyst, PEMFC, Carbon Nanotube, Pt/MWCNT, Pt Distribution, Functionalized MWCNT, Pt Loading

\section{Introduction}

Carbon nanotubes (CNTs) have been an interest nanoscale material with their unique structure depending on their electronical and mechanical properties[1]. They are expected to have a wide range of practical applications such as catalyst supports in heterogeneous catalysis[2], field emitters[3], sensors, gas-storage media[4,5] and molecular wires for next generation electronic devices[6]. CNTs is attractive material for electrocatalyst support due to its high surface area to produce high activity of electrocatalyst[ $[7,8]$. Small size and good distribution nanoparticle along exterior wall of CNT is one of important indicators to produce high activity of electrocatalyst. Although CNTs are attractive materials for many potential applications, it is difficult to disperse, dissolve and react in solvents which causes poor processability. To overcome this limitation, efforts to form an active surface of the CNTs is essential to do. Functionalization of CNT surface is stage that have to be done to create active site which appear as structural defect of hexagonal carbon. Structural defect that arise during the process of functionalization would affect its function as a support of metal catalyst due to changes in the electronical properties $[9,10]$. In the addition to formation of active site, deposition techiques of metal nanoparticle on MWCNT

* Corresponding author:

rikeyudianti@yahoo.com (Rike Yudianti)

Published online at http://journal.sapub.org/nn

Copyright (C) 2012 Scientific \& Academic Publishing. All Rights Reserved surface are primary importance for the successful application. Deposition techniques were investigated to obtain the optimal condition for high number of active surface as metal sites. The controlled coating of metal nanoparticles onto CNTs and the prevention of aggregation of these particles are of primary importance for the successful application of these materials. Several methods have been developed to coat or deposit metals onto CNTs. Among the methods, chemical reduction using polyol method is generally very simple to implement and an attractive choice for large-scale synthesis.

In the previous study, we analyzed extent of damage on the functionalized structures after chemical treatments by Raman spectroscopy and Boehm titration method[11]. The functionalized CNTs were further used as electrocatalyst support in this recent work. Recently, we investigated the effects of nitrogen gas and water on the synthesis of electrocatalyst using polyol method. It is intended to prepare dispersible CNTs decorated with good distribution Pt nanoparticles and its utilization as hybrid nanosystem in electrocatalysis. The synthesis was carried out by chemical reduction using ethylene glycol as reducing agent. Role of nitrogen gas and ethylene glycol simultaneously offers a promising pathway to preparing high $\mathrm{Pt}$ dispersion and loading. Growth, distribution and aggregation of metal nanoparticle on the MWCNT surface was investigated by transmission electron microscope. Pt size distribution on the CNT surface was quantitatively investigated using image processing by imageJ software analyzer. To find out the optimal synthesis condition, the performance of 
own-synthesis electrocatalyst was tested in electro-active surface area by voltametric cyclic in comparing with that's of $\mathrm{Pt} / \mathrm{C}$ electrocatalyst.

\section{Experimental Section}

\subsection{Material}

Multi-wall carbon nanotubes (MWCNTs) were purchased from Chengdu Alpha Nano Tech. Co. Ltd. Spesification of MWCNTs such as purity level of $95 \%$, outer diameter (OD) of $50 \mathrm{~nm}$ and length $5 \mu \mathrm{m}$ are reported. Functionalization of CNTs was done using the method described by Yudianti et al.[11] containing carboxyl group of $31.6 \mathrm{mmol.g}{ }^{-1}$. Hexachloroplatinic acid $\left(\mathrm{H}_{2} \mathrm{PtCl}_{6} \cdot\left(\mathrm{H}_{2} \mathrm{O}\right)_{6}\right)$ obtained from Aldrich 206083 was used as $\mathrm{Pt}$ precursor.

\subsection{Eletrocatalyst Synthesis}

Electrocatalyst A and B were prepared in addition of precursor dissolved in ethylene glycol (EG) and a mixture of water - EG $(2: 3(\mathrm{v} / \mathrm{v}))$, respectively. Nitrogen gas flowed into the reactor to synthesize of A- $\mathrm{N}_{2}$ and $\mathrm{B}-\mathrm{N}_{2}$ electrocatalyst. Effects of water and $\mathrm{N}_{2}$ gas on $\mathrm{Pt}$ size distribution were further evaluated. Preparation of electrocatalyst A, B, A- $\mathrm{N}_{2}$ and $\mathrm{B}-\mathrm{N}_{2}$ are described in detail below :

(A) CNT solution was prepared by dissolving $40 \mathrm{mg}$ of CNTs in EG containing sodium deodecyl sulphate (SDS) as dispersion agent and then dispersed by ultrasonicator. Separately, $30 \mathrm{mg}$ of hexachloroplatinic acid was dissolved in EG as reducing agent to make precursor solution. Precursor solution was slowly dripped into CNT solution for $5 \mathrm{~h}$ under vigorous stirring at $450 \mathrm{rpm}$ and finally ultrasonicated for $3 \mathrm{~h}$. The reaction was performed in alkaline $\mathrm{pH}(\mathrm{pH} 13)$ by addition of $0.1 \mathrm{M}$ sodium hydroxide $(\mathrm{NaOH})$ solution in EG. Reflux was performed at $130^{\circ} \mathrm{C}$ for $3 \mathrm{~h}$, without (sample A) and with (sample A- $\mathrm{N}_{2}$ ) $\mathrm{N}_{2}$ gas flow to isolate oxygen and prevent the production of byproducts.

(B) In this technique, CNT solution was prepared by dissolving $40 \mathrm{mg}$ of CNTs in water and ultrasonicated for $2 \mathrm{~h}$. EG $(30 \mathrm{~mL})$ containing SDS was added to CNT solution and ultrasonicated for a hour. Separately, $30 \mathrm{mg}$ of hexachloroplatinic acid was dissolved in a mixture of water and EG with a ratio of $2: 3(\mathrm{v} / \mathrm{v})$. Thereafter, precursor solution was slowly dripped into CNT solution under vigorous stirring at $450 \mathrm{rpm}$. The final solution was conditioned at $\mathrm{pH} 13$ in addition of $1 \mathrm{M} \mathrm{NaOH}$ in $\mathrm{EG}$ and then reflux at $130^{\circ} \mathrm{C}$ for $3 \mathrm{~h}$, without (sample B) and with (sample B- $\mathrm{N}_{2}$ ) $\mathrm{N}_{2}$ gas flow to isolate oxygen and prevent the production of byproducts.

After reflux, the solution was cooled down and $\mathrm{pH}$ remained at 13. Sample was then acidified by addition of $0.1 \mathrm{M}$ hydrochloric acid $(\mathrm{HCl})$ until $\mathrm{pH} 2$ and stirred overnight. Neutralization of sample was carried out by filtration and washing with water continuously until neutral condition. The neutral electrocatalyst was then dried overnight in oven at $60^{\circ} \mathrm{C}$.

\subsection{Characterization of Electrocatalyst}

Analysis on morphological structure of $\mathrm{Pt} / \mathrm{CNT}$ electrocatalyst was performed by transmission electron microscope (TEM), JEOL JEM 1200EX, operated at accelerating voltage of $80 \mathrm{kV}$. Weight of $0.5 \mathrm{mg}$ electrocatalyst was dispersed in ethanol by ultrasonicator for $2 \mathrm{~h}$, dripped on the surface of TEM grid and allowed to dry in air. Pt loading was determined by energy dispersive $\mathrm{X}$-ray spectroscopy (EDAX) as analytical technique for elemental analysis. Presence of Pt on the CNT surface was analyzed by X-ray diffractometer (XRD), Philips PW 1710. $\mathrm{X}$-ray beam was subjected to the sample using $\mathrm{Cu}-\mathrm{K} \alpha$ source $\left(\lambda=1.54 \mathrm{~A}^{0}\right)$ to obtain XRD spectra of electrocatalyst. The tube current and voltage are $100 \mathrm{~mA}$ and $40 \mathrm{kV}$, respectively. The diffraction angle was scanned from 10 to $100^{\circ}$ at scanning speed of $5^{\circ} / \mathrm{min}$. Avarage particle size $(\mathrm{T})$ was estimated using Debye-Scherrer formula (12) :

$$
\mathrm{T}=\mathrm{K} \lambda /(\mathrm{B} \operatorname{Cos} \theta)
$$

$\mathrm{K}=$ constant dependent on crystallite shape $(0.9)$

$\lambda=\mathrm{X}$-ray wavelength $(0.15406 \mathrm{~nm})$

$\mathrm{B}=$ Full width at half maximum (FWHM)

$\theta=$ Bragg angle

\subsection{Performance Test of Electrocatalyst}

Cyclic voltametry was performed by Gamry electrochemistry system model (G750) completed with three-electrode system. Three electrodes used in the measurement were platinum wire, saturated calomel electrode (SCE) and glassy carbon as counter, reference and working electrodes, respectively. The working electrode was a thin film of nafion-impregnated catalyst casted on glassy carbon surface with active surface area of $0.26 \mathrm{~cm}^{2}$. Catalyst film was prepared by sonication of $20 \mathrm{~mL}$ ethanol containing $7.6 \mathrm{mg}$ catalyst. The dispersed catalyst solution, $50 \mu \mathrm{L}$ was dripped on the the glassy carbon surface and dried in oven at $60^{\circ} \mathrm{C}$ for $30 \mathrm{~min}$. Aqueous nafion was prepared by dissoving $0.25 \mathrm{~mL}$ of $5 \mathrm{wt} \%$ nafion solution in $5 \mathrm{~mL}$ isopropanol by stirring at room temperature. After catalyst completely dried, $10 \mu \mathrm{L}$ aqueous nafion solution was coated on the casted-catalyst surface. The meassurement was conducted in $0.5 \mathrm{M} \mathrm{H}_{2} \mathrm{SO}_{4}$ at room temperature which scanned in the potensial range -0.2 and $1.2 \mathrm{~V}$ vs SCE at scan rate $20 \mathrm{mV} / \mathrm{s}$. The three electrode cell system was purge with nitrogen gas for $30 \mathrm{~min}$ before electrochemical analysis. The coulombic charge for hydrogen adsorption was used to calculate the electrochemistry active surface (EAS) of platinum in electrocatalyst :

$$
\mathrm{EAS}=\mathrm{Qh} /(210 \times \mathrm{m})
$$

Where $\mathrm{m}$ represents the platinum loading in electrode; $\mathrm{Qh}$ is charge for hydrogen desorption ; 210 represents the charge required to oxidize a monolayer of hydrogen from $1 \mathrm{~cm}^{2}$ of platinum black.

\section{Results and Discussion}


Integrated material analysis after electrocatalyst synthesis was performed to determine the performance of electrocatalyst indirectly. In the current study, reaction condition was emphasized on the influence of water and nitrogen gas in the synthesis using polyol method. Performance of CNT-based electrocatalyst synthesized by different technique was investigated on Pt size, distribution and loading on the surface acid group of functionalized MWCNT .

\subsection{Morphological Structure of Electrocatalyst}

Influence of $40 \%$ water and $\mathrm{N}_{2}$ during the synthesis of $\mathrm{Pt} / \mathrm{CNT}$ electrocatalyst using polyol method was observed by transmission electron microscope (TEM) as appropriate techniques to observe surface structure of $\mathrm{Pt} / \mathrm{CNT}$ electrocatalyst. Figure 1 shows morphological structure of
$\mathrm{Pt} / \mathrm{CNT}$ electrocatalyst whereas Pt nanoparticle on CNT surface using chemical reduction in different reaction condition. Sample B and B- $\mathrm{N}_{2}$ (Figure $1 \mathrm{~b}, \mathrm{~d}$ ) show some flocking of Pt nanoparticles as cluster of small-size particle appear on B- $\mathrm{N}_{2}$ after $\mathrm{N}_{2}$ flowed in the reaction system. Contribution of water reduced viscosity of EG inducing high diffusion of nanoparticles in solution. In A- $\mathrm{N}_{2}$, homogeneous Pt nanoparticle distribution seem on the CNT surface indicating $\mathrm{EG}$ and $\mathrm{N}_{2}$ gas have considerable contribution in the formation of well-dispersed $\mathrm{Pt}$ nanoparticle since absence of water. High viscosity of EG cause slow diffusion of Pt for growth and nucleation in stable state. High number of small-size Pt particles which have good contact looks clearly distributed on the whole A- $\mathrm{N}_{2} \mathrm{CNT}$ surface (Fig. 1c).
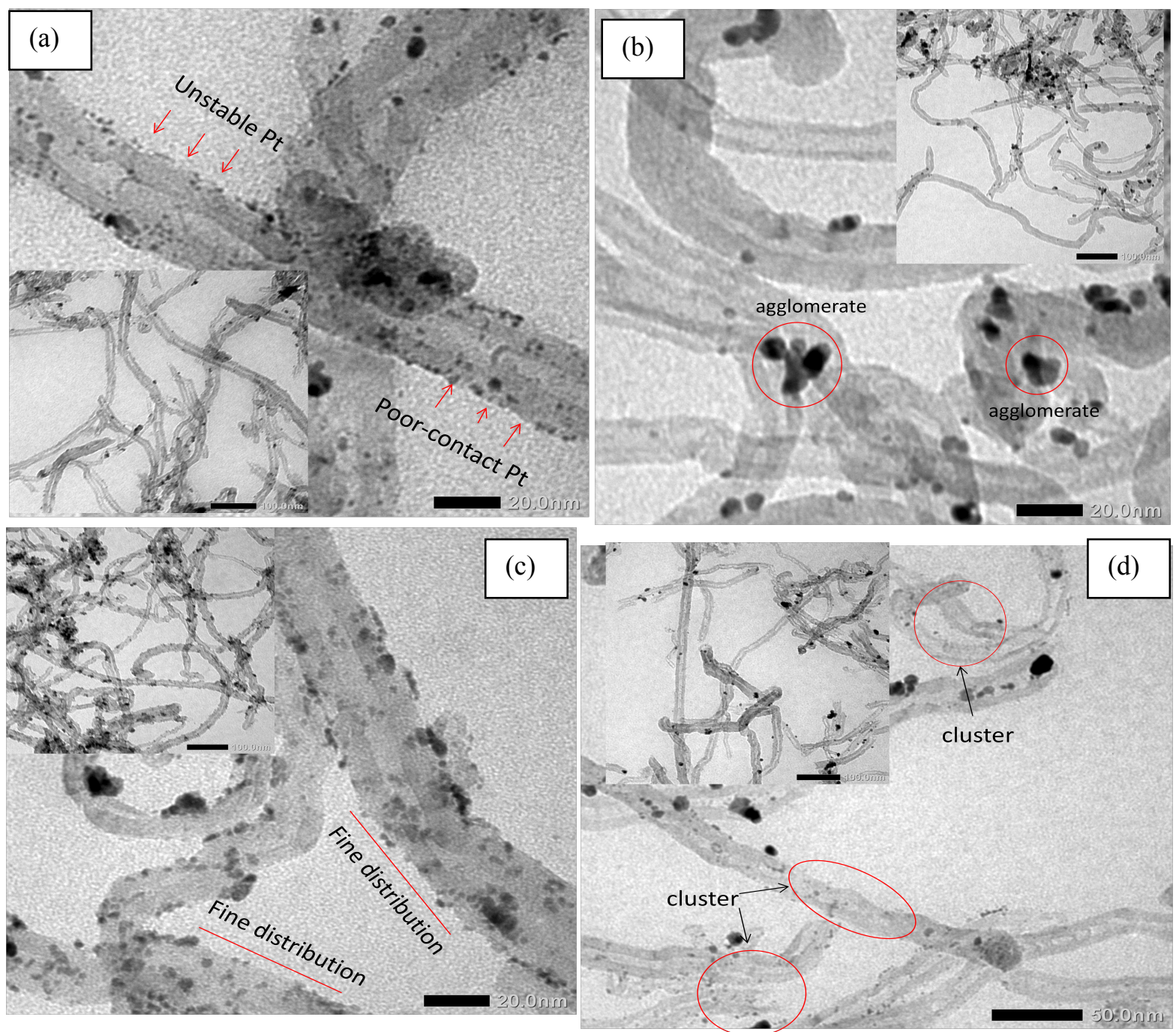

Figure 1. Distribution of Pt particle on CNT surface. (a)Sampel A ; (b) Sample B ; (c) Sample A-N $\mathrm{N}_{2}$; (d) Sample B-N $\mathrm{N}_{2}$ 
Otherwise, a number of unstable-Pt particle seems on the surface of hexagonal carbon of sampel A. It prooves an essential role of $\mathrm{N}_{2}$ gas to form strong interaction of Pt-carbon. For its use as electrocatalyst, deposition should be uniform and stable along exterior wall of CNT over time. effectively stabilizes diffusion of $\mathrm{Pt}$ nanoparticle for nucleation and growth. Role of EG as a stabilizer breaks down to form acetate at high temperatures and stabilize metal colloids[13]. No additional stabilizer is required in the reaction which may be essential to ansure electronic contact between CNT as support and metal nanoparticle. EG stabilize metal bonds to the activated sites on the CNTs. Due to high viscosity, EG prevents the platinum being transported too quickly to the active sites resulting in smaller particle size whereas EG has a steric hindrance effect to inhibit Pt agglomeration[14].

Anyway, a number of smaller particle was also clearly observed in sample $B-\mathrm{N}_{2}$ in which $\mathrm{N}_{2}$ gas contributed in the reaction system (Figure 1d). In this case, important role of $\mathrm{N}_{2}$ gas to create $\mathrm{Pt}$ nucleation and growth was observed. Non-reactive properties of $\mathrm{N}_{2}$ as inert gases is sufficient powerfull to prevent undesirable chemical reactions. At least as counterbalance effect of water to inhibit aggregation. Water content in the reaction highly encourages the formation of $\mathrm{Pt}$ aggregation to be larger particles since the absence of $\mathrm{N}_{2}$ gas. Close relationship between concentration The experimental results confirm that high viscosity of EG

of water and the resulted particles size in the synthesis system was revealed in detail by Li et al. and Knup et al. $[15,16]$.

\subsection{Analysis of Nanoparticle Size Distribution and Loading}

Regarding image analysis, they visually show $\mathrm{Pt}$ distribution on the exterior wall of CNT in different density. EDAXS constitutes one of analytical tools to estimate amount of Pt nanoparticle sited on the exterior wall of CNT (Figure 2). Based on the elemental analysis, electrocatalyst shows no particles other than carbon and platinum. Each synthesis condition promotes differences in Pt distribution and levels. Sample A, B and B- $\mathrm{N}_{2}$ contain almost the same $\mathrm{Pt}$ loading, about $20-23 \%$ (Fig. 2a,b and d) with the particle size about 3.6-5.6 nm (Table 1). In the case of sample A- $\mathrm{N}_{2}$ synthesized under EG dan $\mathrm{N}_{2}$ gas condition shows considerably high Pt loading, 35.0\% with the smaller size of particle about $2.9 \mathrm{~nm}$ (Table 1) in the same amount of precursor solution. Quantity level of $\mathrm{Pt}$ attached on the carbon surface greatly depends on reaction condition. Electrocatalyst A- $\mathrm{N}_{2}$ was synthesized in optimal condition due to high number of Pt particle absorbed by active groups as metal site. It explains important role of $\mathrm{N}_{2}$ gas and ethylene glycol. We compared our synthesis with the commecial electrocatalyst $(\mathrm{Pt} / \mathrm{C})$.
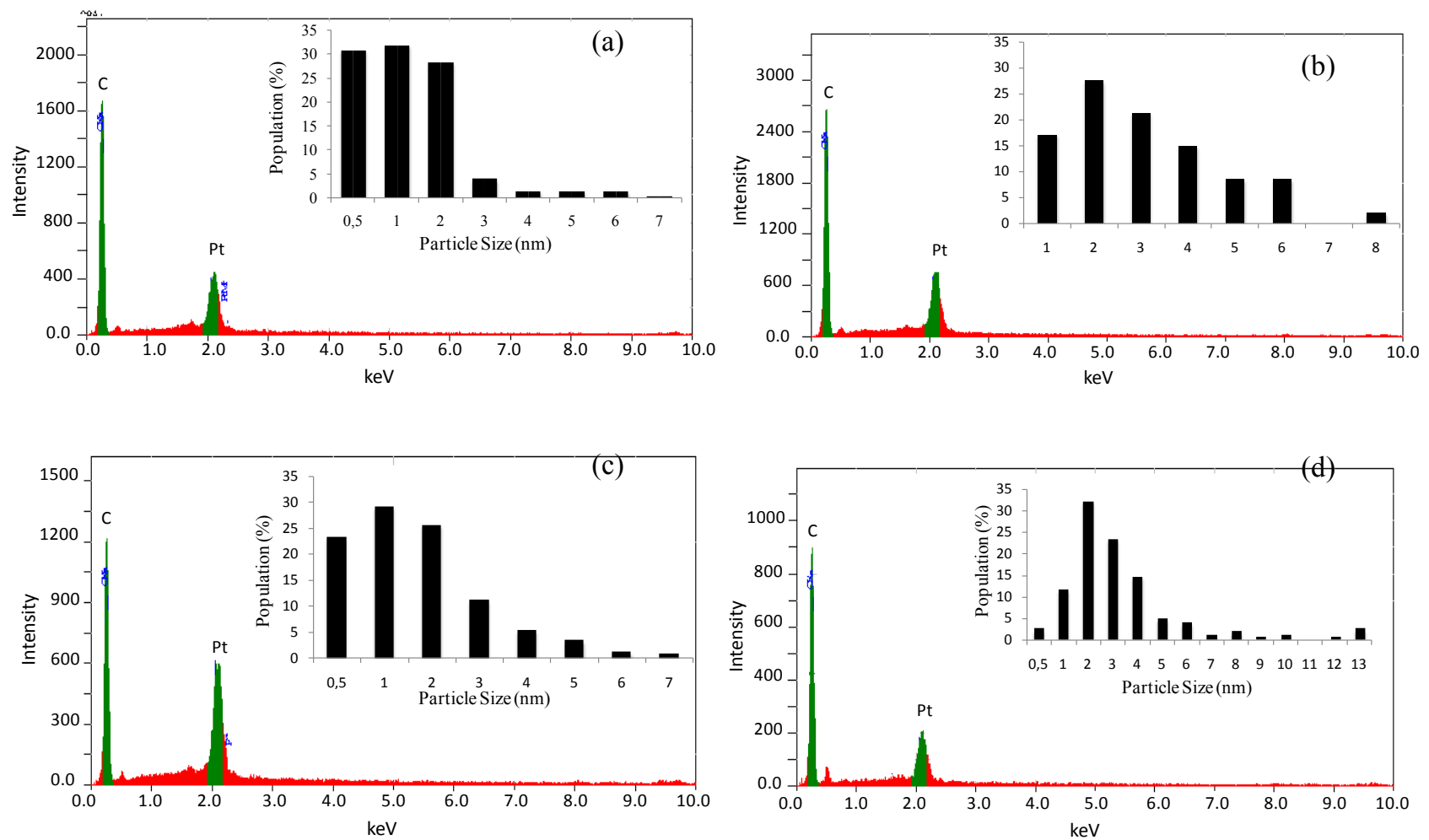

Figure 2. Energy dispersive X-Ray analysis (EDAX) and size distribution of electrocatalyst (Inset Figure). (a) Sampel A ; (b) Sample B ; (c) Sample A-N 2 ; (d) Sample B- $\mathrm{N}_{2}$ 
Pt size distribution could be determined quantitatively from TEM images by imageJ analyzer software. Size distribution of nanoparticle was plotted as histogram graph, shown as inset figure of Figure 2. Based on TEM image, electrocatalyst particles have a spherical shape as individual particle. Due to reaction condition, agglomerate particle tend to be ellipsoidal shape in agglomerate size $>5 \mathrm{~nm}$. Particle size of sample B- $\mathrm{N}_{2}$ (Figure 2d) shows a wide distribution containing particle size from $0.5-13 \mathrm{~nm}$. In TEM image of sample A- $\mathrm{N}_{2}$, image analyzer counted $1.8 \%$ particles of 258 particles in diameter $>5 \mathrm{~nm}$ which could not be separated to small-size particle. Electrocatalyst A- $\mathrm{N}_{2}$ contains quite low number of large particle compared with sample $\mathrm{B}$ and $\mathrm{B}-\mathrm{N}_{2}$ containing $10-10.8 \%$ particle size in diameter $>5 \mathrm{~nm}$. Pt size of electrocatalyst $\mathrm{B}-\mathrm{N}_{2}$ show a very broad distribution from 0.5 to $13 \mathrm{~nm}$. Diameter $>5 \mathrm{~nm}$ is believed due to agglomeration. Visually, Pt loading in sample A- $\mathrm{N}_{2}(35.0 \%)$ looks considerably higher than those of 3 other samples (20-23\% Pt loading). Elactrocatalyst A- $\mathrm{N}_{2}$ contains $258 \mathrm{Pt}$ particles in the area of $30.1 \mathrm{~nm}^{2}$. At the same area, low number of nanoparticle exist in sample A, B and B- $\mathrm{N}_{2}$ about 195, 47 and 202 particles, respectively. Growth of small-size Pt particle $(<1 \mathrm{~nm})$ appear on sample $A-\mathrm{N}_{2}$ and $\mathrm{B}-\mathrm{N}_{2}$ leading to main contribution of $\mathrm{N}_{2}$ gas during synthesized process in despite of higher number of small-size Pt distributed on A- $\mathrm{N}_{2}$ than that's of B- $\mathrm{N}_{2}$. Simultaneous contribution of water and $\mathrm{N}_{2}$ gas causes the formation of wide Pt size distribution in sample B- $\mathrm{N}_{2}$. Samples A- $\mathrm{N}_{2}$ posseses a narrow particle size distribution compared to sample $\mathrm{B}-\mathrm{N}_{2}$, no particles having greater size than $7 \mathrm{~nm}$. In the absence of $\mathrm{N}_{2}$ gas, water has a dominant role to form aggregate particles. In meanwhile, small-size Pt $(<1 \mathrm{~nm})$ was also observed in the sample A. Even, absence of $\mathrm{N}_{2}$ gas create unstable-Pt particle and weak contact to the carbon surface. Role of $\mathrm{N}_{2}$ gas and EG highly responsibles for growth and nucleation of $\mathrm{Pt}$ in stable state. Overall analysis of Pt/CNT electrocatalyst reveal that Pt particle size distribution highly depends on reaction condition of catalytic synthesis.

\subsection{X-ray Diffraction Analysis of Electrocatalyst}

The X-ray diffraction (XRD) of electrocatalyst in different reaction condition is shown in Fig. 3. Prior to deposition, strong diffraction peaks are observed at $43.16^{\circ}, 53.86^{\circ}$ and $78,2^{\circ}$ corresponding to hexagonal carbon structure (100), (004) and (110), respectively. XRD of graphitic particle reflects a symetrical structure of hexagonal carbon in electron transporter. Deposition of $\mathrm{Pt}$ on the oxidized hexagonal carbon in different synthesis condition provided almost similar intensity. Pt loading on the CNT surface shows diffraction peaks at $39.9^{\circ}, 46.3^{\circ}, 67.5^{\circ}$ and $81.4^{\circ}$ corresponding to crystalline plane of Pt (111), Pt (200), Pt (220) and $\mathrm{Pt}(311)$, respectively. Analysis of average particle size was performed on $\mathrm{Pt}$ (220) diffraction lattice by Debye-Scherrer formula as representative of diffraction peak, summarized in Table 1. Contribution of water in the reaction resulted in large size of $\mathrm{Pt}$ as indicated in $\mathrm{B}$ and $\mathrm{B}-\mathrm{N}_{2}$ with $\mathrm{Pt}$ particle sizes about $5.6 \mathrm{~nm}$ and $4.6 \mathrm{~nm}$, respectively. Without water, the synthesis creates small size of Pt nanoparticles distribution in average $2.9 \mathrm{~nm}$ (sample A- $\mathrm{N}_{2}$ ) and $3.6 \mathrm{~nm}$ (sample A). Water accelerates the diffusion process, making growth of unstable particle and tend to be large particle. Pt nanoparticles were homogeneously dispersed on the MWNTs surface of A- $\mathrm{N}_{2}$ with Pt loading nearly $40 \mathrm{wt} \%$. However, we reported a convenient technique to control Pt size distribution as important contribution in electrocatalyst system.

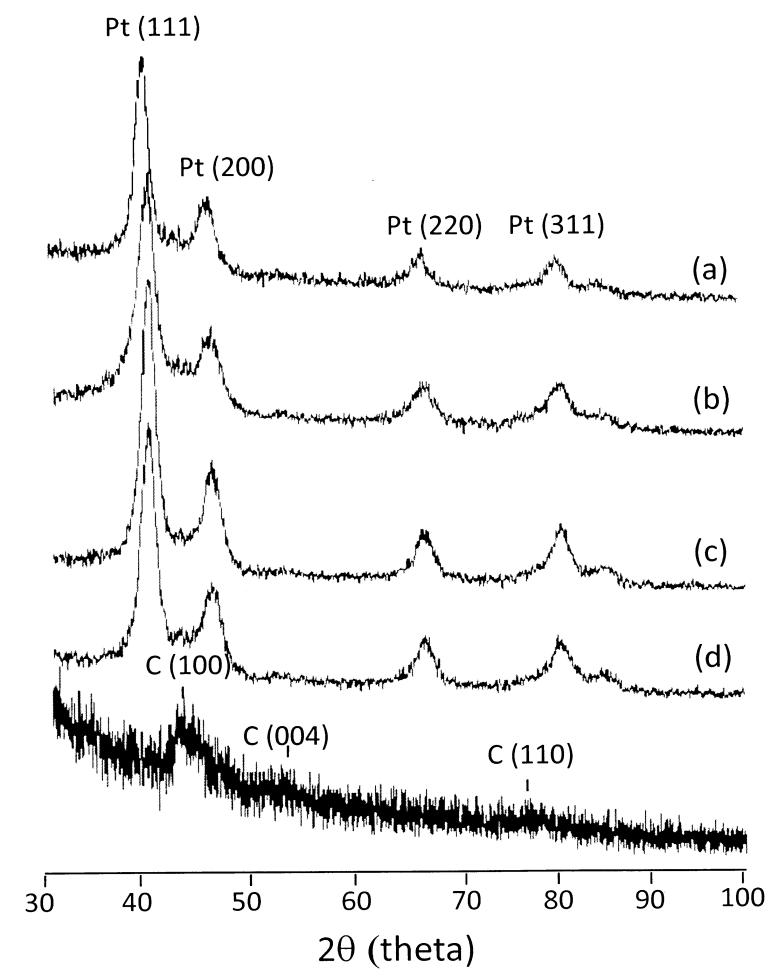

Figure 3. X-Ray diffraction profiles of $\mathrm{Pt} / \mathrm{CNT}$ electrocatalyst on different synthesis techniques. (a) Sampel A;(b) Sample B;(c) Sample A-N ${ }_{2}$;(d) Sample B- $\mathrm{N}_{2}$

Table 1. Pt sizes, loading of $\mathrm{Pt} / \mathrm{CNT}$ and $\mathrm{Pt} / \mathrm{C}$ electrocatalysts

\begin{tabular}{ccc}
\hline Electrocatalyst & Particle Size[nm] & Pt loading[\%] \\
\hline A & 3.6 & 22.9 \\
A-N2 & 2.9 & 35.0 \\
B & 5.6 & 22.1 \\
B-N2 & 4.6 & 20 \\
Commercial & 2.3 & 20 \\
\hline
\end{tabular}

\subsection{Electrochemical Properties of Electrocatalyst}

After material analysis of electrocatalyst, we tested the perfomance of $\mathrm{AN}_{2}-\mathrm{Pt} / \mathrm{CNT}$ to know quality level of synthesis. Cyclic voltametry was employed to obtain the electro-active surface area of the electrocatalyst in order to account for the higher current response. Previously, functionalized-CNT and glassy carbon as background cyclic voltamogram were measured in $0.5 \mathrm{M} \mathrm{H}_{2} \mathrm{SO}_{4}$ in the same 
geometrical area. Functionalized-CNT shows an increasing capasitive current compared with that's of glassy carbon indicating the higher active surface area in the potential range investigated. Without Pt nanoparticle in both sample, no hydrogen oxidation and oxygen reduction appear in voltamogram (Fig. 4a). Figure $4 \mathrm{~b}$ depicts a model voltametric cyclic for CNT-based electrocatalyst compared with commercial catalyst. All the prepared-electrocatalyst exhibits the hydrogen adsorption and desorption peaks between $-0.2 \mathrm{~V}$ and $1 \mathrm{~V}$.
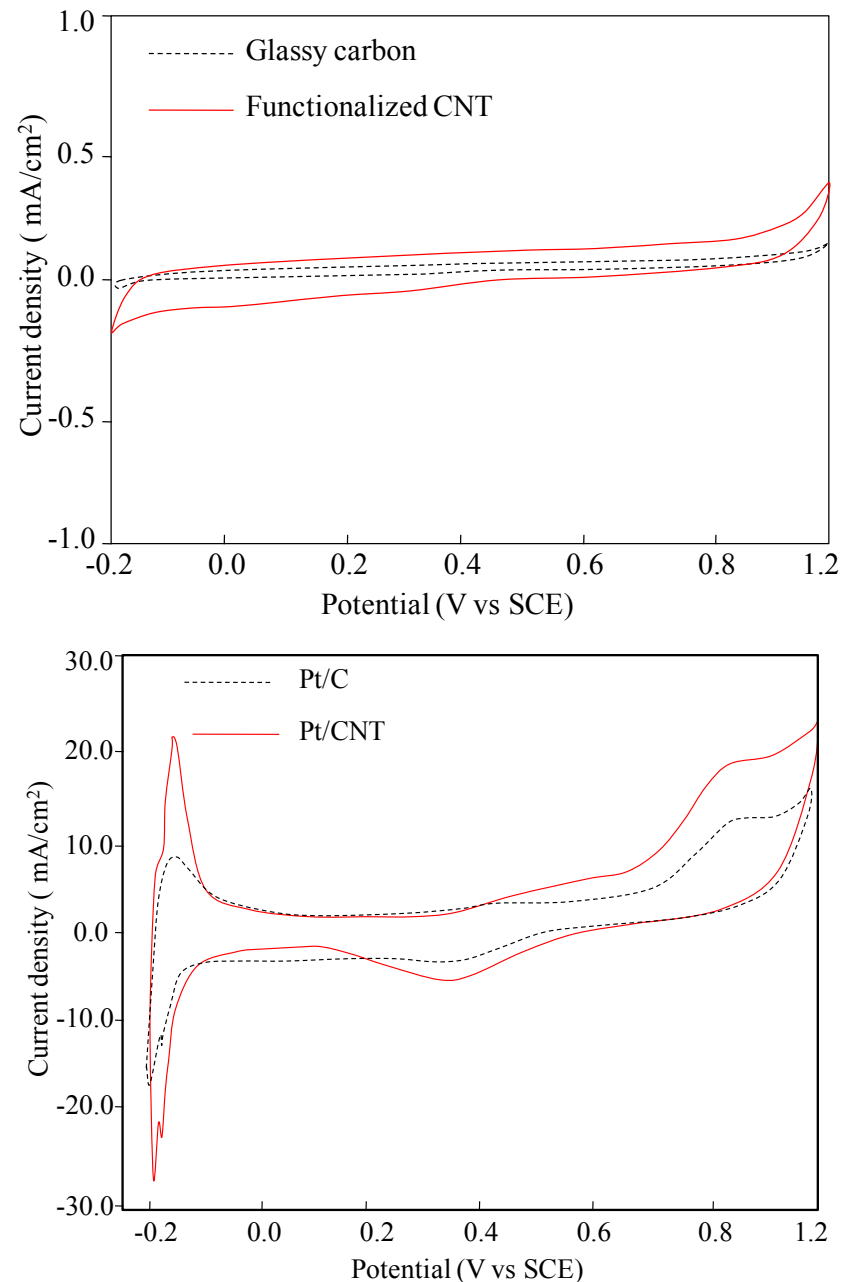

Figure 4. Voltamogram of glassy carbon - functionalized CNT (A) and $\mathrm{Pt} / \mathrm{C}-\mathrm{Pt} / \mathrm{CNT}$ in $0.5 \mathrm{M} \mathrm{H}_{2} \mathrm{SO}_{4}$ (B)

The active Pt surface area of eletrocatalyst was calculated based on the coulombic charge for hydrogen desorption (Qh). The value of $\mathrm{Qh}$ was calculated as the mean value between amount of charge exchanged during the electroadsorption and desorption of hydrogen on Pt sites. The large cathodic current indicates high electrocatalytic activity of Pt/CNT. The electrochemical active area of electrocatalyst was determined from the charge for hydrogen adsorption/desorp tion using Eq. 2 which obtained $3.5 \mathrm{~m}^{2} / \mathrm{g}$ for $\mathrm{Pt} / \mathrm{C}$ and 18.4 $\mathrm{m}^{2} / \mathrm{g}$ for Pt/CNT. Based on the result, there is a great performance in $\mathrm{Pt} / \mathrm{CNT}$ resulted in own-synthesis electrocat alyst indicating CNT gives more efficient in providing $\mathrm{Pt}$ sites which responsible for adsorption-desorption hydrogen.

\section{Conclusions}

The recent study presents an important investigation to study the effect of $\mathrm{N}_{2}$ gas and water content in the synthesis process to determine quality of $\mathrm{Pt} / \mathrm{CNT}$ electrocatalyst. Electrocatalytic synthesis on different reaction conditions provides an overview of differences in structural surface of electrocatalyst. Ethylene glycol and $\mathrm{N}_{2}$ simultaneously contribute to the Pt growth and nucleation in stable state to form narrow particle size distribution along CNT surface. Deposition on the effect of $\mathrm{N}_{2}$ gas and EG constitute effective condition to utilize of surface acid group of hexagonal carbon to produce high $\mathrm{Pt}$ loading (35.0\%). Agglomeration of $\mathrm{Pt}$ nanoparticle in the sample $\mathrm{B}$ and $\mathrm{B}-\mathrm{N}_{2}$ was caused by a critical role of water to form low viscosity solution. Voltamogram of own synthesis - electrocatalyst exhibits good performance in large cathodic current indicating high electrocatalytic activity of $\mathrm{Pt} / \mathrm{CNT}$ by electro-active surface area of $18.4 \mathrm{~m}^{2} / \mathrm{g}$.

\section{ACKNOWLEDGMENTS}

The authors would like to acknowledge financial support from Competitive Programme of Research Center for Physics, Indonesian Institute of Sciences. Great thanks to Dr. Wahyu Nugroho, Departement of Chemistry, Gajah Mada University, Yogyakarta for kind help to get image of transmission electron microscope.

\section{REFERENCES}

[1] Emmenegger, C., P. Mauron, P. Sudan, P. Wenger, V. Hermann, R. Gallay, and A. Züttel, Investigation of electrochemical double-layer (ECDL) capacitors electrodes based on carbon nanotubes and activated carbon materials, J. Power Sources, 124, 321-329, 2003.

[2] Zhang, W., P. Sherrell, A.I. Minett, J.M. Razal, and J. Chen, Carbon nanotube architectures as catalyst supports for proton exchange membrane fuel cells, Energy Environ. Sci., 3,1286-293, 2010.

[3] Heer, W.A, Bonard J M, St"ockli T, Ch`atelain A, Forr'o L, Ugarte D. Carbon nanotubes films: electronic properties and their application as field emitters, zeitschrift F"ur physik, d. 40:418-420, 1997.

[4] Lee S Y, Park S J. Hydrogen adsorption of acid-treated multi-walled carbon nanotubes at low temperature, Bull. Korean Chem. Soc., 31:1596-1600, 2010.

[5] Str"obel R, Garche J, Moseley P T, J"orissen L, Wolf G. Hydrogen storage by carbon materials. J. Power Sources, 159:781-801, 2006.

[6] Dresselhaus MS, Dresselhaus G, Jorio A. Unusual properties and structure of carbon nanotubes. Annu. Rev. Mater. Res., 34:247-78, 2004.

[7] Shaijumon M M, Ramaprabhu S. CNT-Pt/ carbon composites as electrocatalyst for oxygen reduction reaction in pem fuel 
cell. Appl. Phys. Lett., 88:253105, 2006.

[8] Ahmadi T S, Wang Z L, Green T C, Henglein A, El-Sayed M A. Science, 272:1924-96, 1996.

[9] Augustine R L. Heterogeneous catalysis for the synthetic chemist, Marcel Dekker : New York, p. 170, 1996.

[10] Bessel C A, Laubernds K, Rodriguez N M, Baker R T K. Graphite nanofibers as an electrode for fuel cell applications. J. Phys. Chem. B., 105: 1115-1118, 2001.

[11] Yudianti, R., Onggo, H., Sudirman, Saito, Y., Iwata, T., Azuma J. Analysis of functional group sited on multi-wall carbon nanotube surface. J. The Open Mater. Sci., 5 : 242-247, 2011.

[12] J. Zhang. PEM Fuel Cell Electrocatalyst and Catalyst Layer.
Springer-Verlag London Limited, 2008, pp. 559-563.

[13] Chen W, Lee Y,Liu Z. Microwave-assited synthesis of carbon supported pt nanoparticles for fuel cell application. Chem. Comun., 21: 2588-2589, 2002.

[14] Li X, Chen W X, Zhao J, Xing W, Xu Z D. Microwave polyol synthesis of pt/cnts catalysts: Effects of $\mathrm{pH}$ on Partice Size and Electrocatalytic Activity for Methanol Electrooxidization. Carbon, 43:2168-2174, 2005.

[15] Li W, Liang C, Zhou W, Qiu J, Zhou Z, Sun G. Novel in situ synthesis of MWNTs-hyroxyapatite composites. Carbon, 42:423-6, 2004.

[16] Knupp S L, Li W, Paschos O, Murray T M, Snyder J, Haldar P. The effect of experimental parameters on the synthesis of carbon nanotube/nanofiber. Carbon, 46:1276-1284, 2008. 